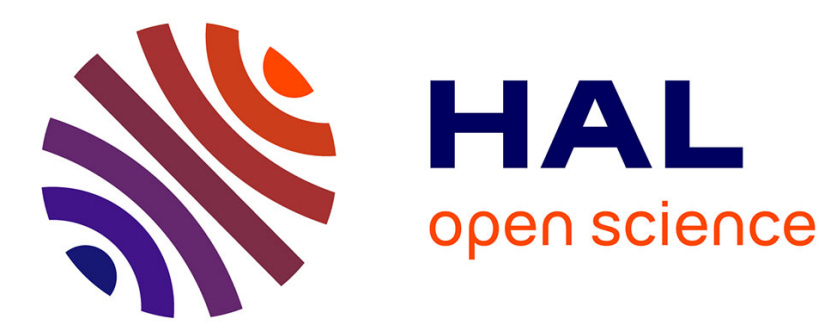

\title{
Toward a sustainable preparation of tunable mesoporous silica
}

Eric Prouzet, Andrew Kacheff, Guillaume Aubert, Ahmed Bentaleb, Rénal Backov, Cyril Aymonier

\section{> To cite this version:}

Eric Prouzet, Andrew Kacheff, Guillaume Aubert, Ahmed Bentaleb, Rénal Backov, et al.. Toward a sustainable preparation of tunable mesoporous silica. Journal of Supercritical Fluids, 2019, 143, pp.139-145. 10.1016/j.supflu.2018.07.008 . hal-01873546

\section{HAL Id: hal-01873546 \\ https://hal.science/hal-01873546}

Submitted on 1 Oct 2020

HAL is a multi-disciplinary open access archive for the deposit and dissemination of scientific research documents, whether they are published or not. The documents may come from teaching and research institutions in France or abroad, or from public or private research centers.
L'archive ouverte pluridisciplinaire HAL, est destinée au dépôt et à la diffusion de documents scientifiques de niveau recherche, publiés ou non, émanant des établissements d'enseignement et de recherche français ou étrangers, des laboratoires publics ou privés. 


\title{
Toward a sustainable preparation of tunable
}

\section{mesoporous silica}

Eric Prouzett, ${ }^{1}$ Andrew Kacheff, ${ }^{1}$ Guillaume Aubert, ${ }^{2}$ Ahmed Bentaleb, ${ }^{3}$ Rénal Backov, ${ }^{3,4}$

\author{
Cyril Aymonier ${ }^{2}$ \\ ${ }^{1}$ University of Waterloo, Dept of Chemistry, 200 University Avenue West, Waterloo, Ontario, \\ Canada N2L 3G1 \\ ${ }^{2}$ CNRS, Univ. Bordeaux, Bordeaux INP, ICMCB, UMR 5026, F-33600 Pessac, France \\ ${ }^{3}$ CNRS, Univ. Bordeaux, CRPP, UMR 5031, F-33600 Pessac, France
}

Corresponding author:

Fax: +1 519 746-0435; tel: +1 519 888-4567 x38172; e-mail: eprouzet@uwaterloo.ca

ABSTRACT. We report how we could circumvent two major drawbacks in the potential scale up synthesis of mesoporous silica via the surfactant-based templating route. First, burning the organic templates to free porosity is costly and not environmental friendly. Most of the mesoporous silica materials show also extremely poor resistance to hydrothermal environments. These drawbacks have certainly contributed to prevent these materials meet practical use, and hampered any possible large-scale manufacturing. Unlike previous reports that claimed that supercritical carbon dioxide $\left(\mathrm{scCO}_{2}\right)$ was ineffective in removing most of the organic templates, except amines, we describe 
how the unique synergy we achieved between $\mathrm{scCO}_{2}$ extraction and our two-step synthesis of mesoporous silica with nonionic templates allowed us to overcome these drawbacks. We conducted different tests, and we report here the preparation of mesoporous materials with tunable pore size between 1 and $10 \mathrm{~nm}$, structure varying from $3 \mathrm{D}$ wormhole to hexagonal, and hydrothermal resistance.

KEYWORDS: mesoporous; silica; synthesis; supercritical; $\mathrm{scCO}_{2}$ 


\section{Introduction}

\subsection{Issues in current manufacturing of mesoporous silica}

Since their identification as well-ordered mesostructured materials [1, 2] after older preliminary works [3], mesoporous silicates have aroused great interest in the community of materials and catalysis, marked by thousands of publications in this domain.[4, 5] Beyond the major breakthrough of a new paradigm in the synthesis of porous materials using molecular assemblies instead of single molecules as templates, hopes were great because these materials were seen as potential candidates for extending heterogeneous catalysis or adsorbents to domains where a pore size larger than zeolites, was required. Among the materials reported until now, probably the most renown are MCM-41 (>4,600 refs with MCM-41 in the title), SBA-15 (>3,100 refs) and HMS (> 850 refs). However, until now, few applications, or even none, have been brought to life. The reasons for this unsuccessful development are multiple, the principal being probably the lack of clear target market, but some others can be found:

(i) Despite many claims, these syntheses lead usually to materials with a unique pore size: $4.0 \mathrm{~nm}, 9.0 \mathrm{~nm}$, and $2.5 \mathrm{~nm}$ for MCM-41 [6], SBA-15 [7], HMS [8], respectively; ways to modify these values were described, but they are rarely used.

(ii) Even though trials with other templates were demonstrated, these syntheses are usually limited to only one single type of template: cetyltrimethylammonium for MCM-41, triblock copolymer Pluronic 123 for SBA-15, and dodecylamine for HMS.

(iii) These syntheses use $40-50 \mathrm{wt} \%$ organic templates, and scaling-up at industrial scale is hampered by the need for removing them to open the porosity. The faster and more efficient is usually via thermal treatment, which leads to an unacceptable costly loss of chemicals and 
environmental impact. Solvent-based extraction has been successful, but too slow to go realistically beyond bench scale.

(iv) Usually, these materials offer a rather low to no resistance to hydrothermal environments, if some specific conditions are not applied, like seeding with zeolites nuclei [9].

\subsection{Specificity of the two-step synthesis of mesoporous silica}

We reported the first synthesis of mesoporous silica with polyethylene oxide (PEO) nonionic copolymers as templates (named MSU-X silica) [10], and we developed a two-step synthesis route [11], which offers many advantages over the initial method: (i) synthesis in mild conditions: water, open air pressure, mild acidity ( $\mathrm{pH} 1-3)$, moderate temperature $\left(20-60^{\circ} \mathrm{C}\right)$; (ii) use of any type of hydrophilic (HLB 9-15) nonionic surfactant including triblock copolymer like Pluronic 123; (iii) for the same template, an additional control of the particle size \& shape, as well as pore size, via the synthesis parameters; (iv) thermodynamic control of the assembly and condensation reactions, with the intermediary formation of stable silicate/organic hybrid micelles, allowing for an easy scaling-up [12].

As for all other methods, the scale-up of this synthesis was still hitting the requirement for a rapid and sustainable non-destructive removal of the organic templates, which could not be provided by the multi-hour thermal treatment we used to apply. However, unlike self-assembly mechanisms of MCM-41 (basic $\mathrm{pH}$ ) or SBA-15 (highly acidic $\mathrm{pH}$ ) that are based on charge density matching, hence strong electrostatic interactions between the organic templates and inorganic building blocks $[13,14]$, the two-step synthesis of MSU-type silica works at a $\mathrm{pH}(1.7-3.5)$ close to the isoelectric point (IEP) of silica [15]. It results that templating proceeds via weaker neutral 
hydrophilic interactions [12], which is expected to ease a solvent-based extraction of surfactants, as already demonstrated with HMS materials [8].

\subsection{Advantages of $\mathrm{ScCO}_{2}$ as a green solvent}

In industry, "green chemistry" processes using supercritical carbon dioxide $\left(\mathrm{scCO}_{2}\right)$ as a solvent, are now favored [16-18]:[19], and $\mathrm{scCO}_{2}$ is now used as a routine reacting medium, especially for the synthesis of nanomaterials $[16,20]$. Very few studies have actually combined mesoporous materials with $\mathrm{scCO}_{2}$ : to our knowledge, it was only used as a reacting medium or additive in the synthesis of mesoporous materials [21-25], as an "impregnation" agent for incorporating active molecules in mesoporous matrices [26-28], and only as an extraction agent for amine templates in the synthesis of HMS [29-31], and for the extraction of fluoronic surfactants from mesoporous thin films [32].

\subsection{Objectives and main outcomes of our study}

We demonstrate in the following how the combination of $\mathrm{scCO}_{2}$ as an extractive agent, with the two-step synthesis of MSU silica, creates a unique synergy that allowed us to validate a rapid and facile extraction of templating molecules. These first results open up the way to future easy to scale-up manufacturing, with a cost-effective sustainable synthesis of structurally tunable mesoporous silica. In this preliminary report, we explore the potential of this method, identify the significant parameters, and describe the structural differences resulting from both (thermal and $\mathrm{scCO}_{2}$ ) extraction methods. We present also promising results regarding the good resistance of these materials to hydrolysis, another challenge for the industrial use. This resistance might be improved further when we will combine well-known methods, which is not covered in this short communication [33-35]. 
All syntheses were conducted according to the double-step synthesis of MSU silica as reported before [36]. Details are given in the Electronic Supplementary Information (ESI). This synthesis involves the formation of stable silicate/surfactant hybrid micelles at a $\mathrm{pH}$ 1-3, in water. This $\mathrm{pH}$ allows for the hydrolysis of the silicon alkoxide (TEOS), but not silica condensation. The silicate oligomers resulting from hydrolysis, create hydrophilic interactions with the oxygen atoms on the PEO chains, leading to stable hybrid micelles [12]. The precipitation of silica is induced by the addition of a fluoride salt (eg. NaF), the fluoride ion acting as a silica condensation catalyst [37]. The temperature-dependent reversible swelling of nonionic micelles is still observed in the hybrid micelles, and variation of the synthesis temperature, can easily help to adapt the final pore size within a 2.0 to $6.0 \mathrm{~nm}$ range, of even higher when Pluronic P123 is used [38].

In the usual process, the as-synthesized materials are dried, then calcined at $600^{\circ} \mathrm{C}$ during a $13 \mathrm{~h}$ total thermal treatment in air. With the new method, the as-synthesized powder obtained after filtration, is dispersed in ethanol in an ultra-sound bath for 5 minutes, to dilute as much as possible the remaining water with ethanol, before being recovered by filtration. The washing ethanol can be recovered and reused many times. Since the aim of this preliminary study was to validate the effectiveness of this process, the powders were purposely placed for a limited time (30 min) in a continuous flow $\mathrm{scCO}_{2}\left(35^{\circ} \mathrm{C}, 100 \mathrm{bar}\right)$. The powder was then recovered and used without any further treatment. This new method offers many advantages: (i) the surfactant remains intact and can be reused, since it can be recovered pure at the outlet of the reactor $\left(\mathrm{CO}_{2}\right.$ is released as a gas), (ii) the time required for this surfactant extraction is drastically reduced, with around one hour total including the pressure and temperature adjustment in our bench top apparatus, compared to 13 hours for the thermal treatment, (iii) there is a major energy saving since heating furnaces are 
not required, (iv) the process does not release effluents or produces flue gas, and (v) it is even possible to reuse the washing ethanol involved in this process.

We observed also that the structure of materials obtained via our new $\mathrm{scCO}_{2} /$ two-step synthesis is improved, and present larger pores and higher crystallinity. This is due to the absence of thermal treatment, which prevents any shrinkage and stress of the silica framework.

As examples of this method, we describe now the materials resulting from syntheses carried out at different temperatures $\left(6^{\circ} \mathrm{C}, 21^{\circ} \mathrm{C}, 35^{\circ} \mathrm{C}, 45^{\circ} \mathrm{C}\right)$ with two templates representative of the large range of possibilities offered by this method: an alkyl-PEO diblock copolymer (TergitolTM 15S12: $\mathrm{C}_{15}$-(EO) 12 ; samples referred as "T15S12" in the following), and a triblock copolymer (Pluronic ${ }^{\mathrm{TM}} \mathrm{P} 123$ : $\mathrm{PEO}_{20}-\mathrm{PPO}_{70}-\mathrm{PEO}_{20}$; samples referred as "P123" in the following). The mesostructure of silica synthesized with the two-step method, and especially with P123, is highly dependent on the synthesis temperature, because both the Critical Micelle Temperature (CMT) and Cloud Point (CP) affect the structure and dynamic of hybrid micelles, hence the final structure of silica.[38] For our comparison between the two extraction methods (thermal \& $\mathrm{scCO}_{2}$ ), materials were from the same batch, and half were thermally treated, and half $\mathrm{scCO}_{2}$ extracted.

\section{Experiments}

\subsection{Materials and syntheses}

Synthesis with Tergitol 15S12: In a typical synthesis, TEOS (tetraethylorthosilicate $\mathrm{Si}\left(\mathrm{OCH}_{2} \mathrm{CH}_{3}\right)_{4}$, Sigma Aldrich Chemicals, $\left.\mathrm{Mw}=208 \mathrm{~g}\right)$ was dispersed in a $0.02 \mathrm{M}$ solution of Tergitol 15S12 ([CH $\left.3\left(\mathrm{CH}_{2}\right)_{14}(\mathrm{EO})_{12}\right]$, Dow Chemicals, $\mathrm{Mw}=756 \mathrm{~g}$; EO: ethylenoxide $)$ up to a TEOS/surf. molar ratio of 10 . TEOS is hydrolyzed by the acidic medium, but the $\mathrm{pH}$ value corresponds to the minimum of the silica condensation kinetics, which prevents the silicate 
oligomers resulting from hydrolysis, to react and precipitate. Instead, they interact with the micelles of copolymers to form silicate/organic hybrid micelles. Once stabilized, sodium fluoride $(\mathrm{NaF})$ was used as a reaction catalyst to induce silica condensation, with a NaF/TEOS molar ratio equal to 0.01 .

$7.5 \mathrm{~g}$ of Tergitol $15 \mathrm{~S} 12$ was dissolved at room temperature in $500 \mathrm{~mL}$ of deionized water, acidified beforehand at $\mathrm{pH} 2$ with $\mathrm{HCl}$. After full dissolution, $20.8 \mathrm{~g}$ of TEOS were added under mechanical stirring tuned to allow the TEOS droplets to be well-dispersed enough within the aqueous solution. The solution, initially turbid as a result of the TEOS oily droplets, turned progressively transparent within 10 minutes, once the whole TEOS had been fully hydrolyzed. The remaining solution was left at rest in a fridge $\left(6^{\circ} \mathrm{C}\right)$ overnight, to achieve the full formation of silicate/organic hybrid micelles. This mother solution was left at $6^{\circ} \mathrm{C}$ and aliquots were taken off as required. This achieved the first step (the assembly step) of this two-step synthesis.

$100 \mathrm{~mL}$ aliquots of the mother solution were taken off, left to return (if required) at room temperature, then set at the suitable temperature: $6^{\circ} \mathrm{C}$ (fridge), $21^{\circ} \mathrm{C}$ (room temperature), $35^{\circ} \mathrm{C}$ or $45^{\circ} \mathrm{C}$ (thermostated bath). Each aliquot contained $4.16 \mathrm{~g}$ TEOS ( $\left.0.02 \mathrm{~mol}\right)$ and $1.5 \mathrm{~g}$ Tergitol 15S12; $0.8 \mathrm{~mL}\left(2.10^{-4} \mathrm{~mol}\right)$ of a $0.25 \mathrm{M}$ aqueous solution $\mathrm{NaF}$ were added to achieve a $0.01 \mathrm{NaF} / \mathrm{TEOS}$ molar ratio. The fluoride ion of $\mathrm{NaF}$ is used as a condensation catalyst. This achieved the second step (the silica condensation step) of this two-step synthesis.

The solutions were left at the required temperature for the whole reaction time: $72 \mathrm{~h}$ for the $6^{\circ} \mathrm{C}$ synthesis, $48 \mathrm{~h}$ for the $21^{\circ} \mathrm{C}$ synthesis, and $24 \mathrm{~h}$ for the $35^{\circ} \mathrm{C} \& 45^{\circ} \mathrm{C}$ synthesis. These reaction time were chosen to be sure that the reaction was fully achieved, but most of it was usually achieved within the first couple of hours (except for the reaction at $6^{\circ} \mathrm{C}$ ). The as-synthesized powders were filtered and dried at $60^{\circ} \mathrm{C}$ overnight. 
When applied, the powders were calcined in air with the following procedure: a $3^{\circ} \mathrm{C} \cdot \mathrm{min}^{-}$ ${ }^{1}$ ramp, with a $4 \mathrm{~h}$ plateau at $220^{\circ} \mathrm{C}$, a $2 \mathrm{~h}$ plateau at $450^{\circ} \mathrm{C}$, and a $4 \mathrm{~h}$ plateau at $600^{\circ} \mathrm{C}$. The whole thermal treatment lasted for 13 hours.

When applied, the extraction with supercritical $\mathrm{CO}_{2}$ (denoted $\mathrm{scCO}_{2}$ in the following) was proceeded in a small cylindrical autoclave, under $\mathrm{CO}_{2}$ flow, at $35^{\circ} \mathrm{C}$ and 100 bars, for $30 \mathrm{~min}$. The whole procedure took 45 minutes. Compared with the thermal treatment, the dried powders had been left in ethanol for $5 \mathrm{~min}$. under sonication, to exchange as much as possible the impregnated water with alcohol. The ethanol used for this process can be reused multiple times as it is mostly used as a "washing" solvent.

Synthesis with Pluronic P123: All procedures were similar to those used with Tergitol 15S12, except for the amount of reagents: 7.5g of Pluronic P123 ([(EO $\left.)_{20}(\mathrm{PO})_{70}(\mathrm{EO})_{20}\right]$, Sigma Aldrich Chemicals, $\mathrm{Mw} \approx 7,750 \mathrm{~g}$; EO: ethylenoxide, $\mathrm{PO}$ : propyleneoxide) was added into $500 \mathrm{~mL}$ of deionized water at $\mathrm{pH}$ 2. 33.3g TEOS were added. The rest of the procedure was similar.

Resistance to hydrothermal conditions: Some samples were also tested against aqueous hydrolysis to probe their resistance to hydrothermal conditions: (i) samples after $\mathrm{scCO}_{2}$ extraction or calcination at $600^{\circ} \mathrm{C}$, were sunk into hot water $\left(90^{\circ} \mathrm{C}\right)$ for $3 \mathrm{~h} ; \mathrm{scCO}_{2}$ extracted samples were thermally treated at $400^{\circ} \mathrm{C}$ for $2 \mathrm{~h}$, then sunk into hot water $\left(90^{\circ} \mathrm{C}\right)$ for $3 \mathrm{~h}$.

\subsection{Experimental.}

The samples were characterized by small angle X-ray scattering (SAXS) on a Nanostar (Bruker Co.), equipped with a Siemens Copper anode $(40 \mathrm{kV}, 35 \mathrm{~mA})$. The apparatus is equipped with two crossed Goebel mirrors in order to select the $\mathrm{CuK} \alpha$ wavelength $(0.154 \mathrm{~nm})$ and produces a parallel beam, the final collimation being adjusted with a 3-pinhole setup (with a $300 \mu \mathrm{m}$ diameter for pinhole- 2 setting the beam size). SAXS patterns were acquired using a $22 \times 22 \mathrm{~cm} 2 \mathrm{D}$ gas detector HiStar from Bruker Co., positioned at a distance D of the sample. Silver behenate was 
used as a calibration standard, yielding $\mathrm{D}=1.06 \mathrm{~m}$. The scattering wave vector range used was 0.1 $-2.0 \mathrm{~nm}^{-1}$.

The $\mathrm{N}_{2}$ adsorption isotherms were measured with a Quantachrome AUTOSORB-1. The samples were outgassed at $200^{\circ} \mathrm{C}$ under vacuum for $12 \mathrm{~h}$ before the measurement. Surface area was determined by the BET method in a relative pressure range of $0.05-0.25$.

The samples were dried in a 60C oven and the TGA (TA-Instruments) were ran from 25$600 \mathrm{C}$ at $2 \mathrm{C} \cdot \mathrm{min}^{-1}$.

The set-up for $\mathrm{CO}_{2}$ extraction is composed of a reactor in stainless steel (volume $\mathrm{V}=$ $20 \mathrm{~mL}$ ) with a frit in stainless steel (porosity : $5 \mu \mathrm{m}$ ) heated at $35^{\circ} \mathrm{C}$ and pressurized at 100 bar. The pressure of $\mathrm{CO}_{2}$ is increased thanks to a high pressure pump (Milton Roy, MD23) and is injected in the reactor continuously at the operating pressure with a flowrate of $0.7 \mathrm{~L} / \mathrm{h}$. This pressure is controlled with a back pressure regulator (Jasco, BP-2080plus).

\section{Results and Discussion}

3.1 Efficiency and influence of the $\mathrm{scCO}_{2}$ extraction.

We validated first the actual extraction of organics by TGA (Figure 1).

\section{INSERT HERE FIGURE 1}

Mass loss relevant to organics is the difference between the as-synthesized (blue line) and calcined (green dotted) losses after $150^{\circ} \mathrm{C}$. For $\mathrm{T} 15 \mathrm{~S} 12$ prepared at $35^{\circ} \mathrm{C}$ (Figure 1a), this loss is $(46-22)=24 \mathrm{wt} \%$ of the total dried mass at $150^{\circ} \mathrm{C}$. The $\mathrm{scCO}_{2}$ extraction contributes to the extraction of $(46-24) /(46-22)=92 w t \%$ of the organics, in only 30 minutes. For P123 prepared at $6^{\circ} \mathrm{C}$ (Figure $1 \mathrm{~b}$ ) and $45^{\circ} \mathrm{C}$ (Figure 1c), the extraction is $55 \mathrm{wt} \%$ and $52 \mathrm{wt} \%$ of the total organics, 
respectively. So, TGA confirms the actual, still not complete, extraction of organic templates even after a rather short $(30 \mathrm{~min})$ extraction time. We assign the difference in extraction efficiency to differences in pore morphology. Silica prepared with T15S12 have a highly connected 3D wormhole porous framework, while the synthesis with $\mathrm{P} 123$ at $6^{\circ} \mathrm{C}$ leads to small micropores, and long straight mesopores for the $45^{\circ} \mathrm{C}$ synthesis.

SAXS peak intensity results from two parameters: (i) the electron density contrast between the walls and pores [39], and (ii) cristallinity referred as the order of the porous structure. TGA results showing a lower extraction of organics for $\mathrm{scCO}_{2}$, compared to thermal treatment, tells us that any higher SAXS peak intensity for $\mathrm{scCO}_{2}$ extracted samples will only result from a higher cristallinity.

The SAXS of samples prepared with T15S12 (Figure 2a\&b \&Table S1 in ESI) display the single correlation peak resulting from their 3D wormhole structure [10]. As the synthesis temperature increases, the diffraction peaks shift toward smaller q (resp. larger d-spacing) as a result of a pore size increasing [40]. When compared with thermal treatment, materials prepared with $\mathrm{scCO}_{2}$ extraction display two major variations. First, the intensity of the correlation scattering peak is higher, which we assign to a better crystallinity.

\section{INSERT HERE FIGURE 2}

Secondly, this peak points out at a smaller value of q (resp. larger d-spacing), as a result of a larger pore-to-pore distance. Correlations peaks of calcined samples appear at a higher q (resp. shorter d-spacing) as a result from the temperature-induced shrinkage of the silica framework. This is obviously not observed with the $\mathrm{scCO}_{2}$ extraction. However, as demonstrated below, it is worth reminding that both pore size and wall thickness contribute to the pore-to-pore distance. 
Compared to T15S12, samples prepared with P123 display a broader variation of their SAXS pattern (Figure 2c\&d, and Figure S1 in ESI) [38]. The sample prepared at $6^{\circ} \mathrm{C}$, below the CMT, does not possess any mesostructure, because fully hydrophilic copolymers, create only microporosity. From $21^{\circ} \mathrm{C}$ up to $45^{\circ} \mathrm{C}$, several diffraction peaks are observed, in the ratio $1 ; \sqrt{3} ; 2$; $\sqrt{7}$, corresponding to the (10), (11), (20), and (21) diffraction planes in a 2D hexagonal structure, respectively (Table $\mathrm{S} 1)$. Since the peak intensity between calcined (Figure $2 \mathrm{c}$ ) and $\mathrm{scCO}_{2}($ Figure $2 \mathrm{~d}$ ) is rather similar, despite the remaining presence of $50 \%$ organics in the pores in $\mathrm{scCO}_{2}$, we assume that the reduction in electron density contrast must be balanced by a higher cristallinity for the $\mathrm{scCO}_{2}$ samples. The same shift toward smaller q (resp. larger d-spacing) between thermally treated and $\mathrm{scCO}_{2}$ extracted samples is also observed.

Figure 3 displays the Pore Size Distribution (PSD) (Figures S4 \& S5 in ESI for individual curves) calculated from the nitrogen adsorption isotherms (Figure S2 \& S3 in ESI) [41].

\section{INSERT HERE FIGURE 3}

All samples display open porosity, except for the $\mathrm{scCO}_{2}$ extracted $\mathrm{P} 123$ sample synthesized at $6^{\circ} \mathrm{C}$. This material is microporous because copolymers below the CMT do not create micelles [38], and TGA confirmed that the same percentage of organics was removed, as for the sample prepared at $45^{\circ} \mathrm{C}$ that exhibits opened porosity. We conclude that the remaining molecules block access to these small micropores, while it cannot happen when larger mesopores are involved.

These analyses confirm that the PSD increases with the synthesis temperature, and that the pore size is larger for $\mathrm{scCO}_{2}$ extracted samples than for thermally ones. The silica wall thickness was deduced by subtracting the pore diameter from the $d$-spacing (or a $=2 \mathrm{~d}_{(10)} / \sqrt{3}$ for 
hexagonal phases). These parameters (BET specific surface, pore size distribution (PSD), pore volume, surface roughness) are compared (Figure 4) for T15S12 and P123 samples prepared at $45^{\circ} \mathrm{C}$, and submitted to different extraction (thermal or $\mathrm{scCO} 2$ ) or hydrothermal treatments. Other parameters (BET, PSD, porous volume, wall thickness are compared in Figure S6 for T15S12 and P123 samples prepared at different temperatures an d either calcined or $\mathrm{scCO} 2$ extracted. All values are given in Table S1).

\section{INSERT HERE FIGURE 4}

Comparisons of results from Figure 4 \& S6 reveal the following main observations: (i) the BET surface is similar (Figure 4a) or smaller (Figure $\mathrm{S} 6 \mathrm{a}: 6,21,35^{\circ} \mathrm{C}$ ) for the $\mathrm{scCO}_{2}$ samples than for the calcined ones. It is obviously smaller for the P123 sample (Figure 4a, bottom) because only $50 \%$ organics remain; (ii) the PSD (Figure $4 \mathrm{~b} \& \mathrm{~S} 6 \mathrm{~b}$ ) is always higher for the $\mathrm{scCO}_{2}$ samples, due to the lack of structure shrinking; (iii) the mesoporous volume (Figure 4c \& S6c) is quite similar (except for P123 because of the remaining organics); (iv) the silica surface roughness (Figure 4d) quantified by the Surface fractal dimension Ds, remains in the same range (see below); (v) the silica wall thickness (Figure S6d) is always higher for the $\mathrm{scCO}_{2}$ extracted samples.

We conclude from these observations that the $\mathrm{scCO}_{2}$ extraction is an effective process for quickly removing the organic templates, without burning them, in a quicker and more sustainable way. The lack of thermal treatment reduces the stress on the silica structure and preserves a larger pore size and thicker silica walls. These values (larger pore, thicker silica wall, same pore volume) result physically into a smaller BET surface.

\subsection{Resistance to hydrolysis.}


We ran also some tests to see how these materials can resist hydrothermal conditions. We left samples prepared at $45^{\circ} \mathrm{C}$ with $\mathrm{T} 15 \mathrm{~S} 12$ or $\mathrm{P} 123$, in water at $90^{\circ} \mathrm{C}$ for $3 \mathrm{~h}$, then analyzed them by $\mathrm{N}_{2}$ adsorption. For the $\mathrm{scCO}_{2}$ treated samples, an alternative route was tested, with a thermal annealing at $400^{\circ} \mathrm{C}$ for $2 \mathrm{~h}$ after $\mathrm{scCO}_{2}$ extraction, before being exposed to water. The $\mathrm{N}_{2}$ isotherms are displayed in Figures S7 and S8 for T15S12 and P123, respectively, and the PSD in Figure S9 and S10. Figure 4 displays the comparison between four physico-chemical parameters (see Table S2 for values, and Figures S7 to S12): (a) BET surface area, (b) pore size distribution, (c) pore volume, and (d) the surface fractal dimension. The surface fractal dimension Ds was calculated from the adsorption branch of the $\mathrm{N}_{2}$ isotherm [42]. Ds is a good gauge of the surface roughness, and expected to vary between 2 (smooth) and 3 (very rough).

These tests show that the mesoporous silica presents a rather good resistance to hydrolysis, and do not collapse rapidly. For (T15S12 \& P123) samples calcined at $600^{\circ} \mathrm{C}$, the influence of hydrolysis $\left(600^{\circ} \mathrm{C}+\mathrm{H}_{2} \mathrm{O}\right)$ on the material structure leads to: (i) a $30 \%$ reduction of the specific surface; (ii) a pore size being unchanged; (iii) no obvious correlation with the pore volume: increasing for T15S12 and decreasing for P123; (iv) an unchanged fractal surface dimension Ds.

Values of Ds are in agreement with previous reports [42]: they are significantly higher $(\mathrm{Ds}=2.74)$ for $\mathrm{P} 123$ than $\mathrm{T} 15 \mathrm{~S} 12(\mathrm{Ds}=2.4)$, which means that silica prepared with $\mathrm{P} 123$ presents a rougher surface than prepared with $\mathrm{T} 15 \mathrm{~S} 12$. Ds, hence the roughness, is not modified after water treatment, which means that this roughness is intrinsic to the silica structure. The materials resist overall quite well to hydrolysis, and except for the BET surface, no noticeable change is observed. This is confirmed by the $\mathrm{N}_{2}$ isotherms (Figures $\mathrm{S} 7 \& \mathrm{~S} 8$ ) that the silica structure remains similar, with the same curve profiles, and only a vertical shift for the sample prepared with P123, as a result of a lower surface. 
For samples extracted with $\mathrm{scCO}_{2}$, different observations are made: (i) a $30 \%$ reduction of the specific surface is observed for T15S12, and none for P123, but this latter was already significantly low; (ii) the pore size remains unchanged; (iii) no obvious correlation with the pore volume: at the opposite of thermally treated samples, it is decreasing for T15S12 and increasing for P123; (iv) the value of Ds is similar for T15S12, compared to the calcined samples, and lower with P123 (smoother surface). Both are slightly reduced after water treatment, but it is within the error range.

In a final test, we assessed if a thermal post-treatment at $400^{\circ} \mathrm{C}$ after $\mathrm{scCO}_{2}$ extraction could improve the material resistance (" $\mathrm{CO}_{2}+400^{\circ} \mathrm{C}$ " samples). This post-treatment aims at removing any organic residue and increasing the silica framework reticulation (increase oxolation $v s$ olation). Such a post-treatment could be considered in an industrial process.

Compared with samples only extracted (" $\mathrm{CO}_{2}$ "), the " $\mathrm{CO}_{2}+400^{\circ} \mathrm{C}$ " samples, present some surprising differences that reveal that the chosen temperature for this preliminary test is not optimum: (i) the BET surface is unchanged for T15S12 (963 to $\left.946 \mathrm{~m}^{2} \cdot \mathrm{g}^{-1}\right)$ and significantly improved for P123 (from 184 to $434 \mathrm{~m}^{2} \cdot \mathrm{g}^{-1}$ ), since organics left in the P123 sample are probably removed by the thermal treatment (the pore volume increases upon thermal post-treatment); (ii) the pore size does not fluctuate significantly; (iii) its volume is reduced for T15S12, but increases for P123 (see above); (iv) finally, the surface roughness is also unchanged for T15S12 and increases for P123.

The variation observed for the sample prepared with $\mathrm{P} 123$ shows that a $30 \mathrm{~min} \mathrm{CO}_{2}$ extraction is effective, but probably too short for a complete extraction. Further studies will explore the influence of the treatment time on the organic removal efficiency. 
We finally studied how these " $\mathrm{CO}_{2}+400^{\circ} \mathrm{C}$ " samples can resist to hydrolysis ((" $\mathrm{CO}_{2}+$ $400^{\circ} \mathrm{C}+\mathrm{H}_{2} \mathrm{O}$ " samples). Our observations lead us think that this post-treatment temperature is not optimized toward hydrolysis because it leaves the silica framework in an intermediary unconsolidated state: (i) BET surfaces are drastically reduced for both samples: T15S12 (from 946 to $313 \mathrm{~m}^{2} \cdot \mathrm{g}^{-1}$ ) and P123 (from 434 to $129 \mathrm{~m}^{2} \cdot \mathrm{g}^{-1}$ ); (ii) the pore size does not vary significantly for P123 while it is totally shifted to larger values (between 5 and 30nm) for T15S12, most probably as a result of the mesostructure collapse; (iii) variations of the pore volume are uncorrelated; (iv) the fractal surface dimension Ds is reduced for P123, and unchanged with T15S12.

These preliminary results on the influence of a thermal post-treatment are not still fully conclusive. If it does not modify drastically the structure of samples prepared with $\mathrm{T} 15 \mathrm{~S} 12$, it contributes to remove the remaining surfactants left behind in the P123 sample, since the $30 \mathrm{~min}$ extraction with $\mathrm{scCO}_{2}$ was apparently not long enough to allow full extraction for these samples, as a result of the specific microstructure of the P123 samples (long pores).

The influence of this post-treatment on the material stability against hydrolysis is mostly negative. We observed a significant reduction in the BET specific surface, and the T15S12 structure most probably collapsed, or at least lost its mesoscopic order. We believe that this rather low temperature, has the main effect of activating the silica surface by cleaning the remaining organics, but is probably too low to consolidate the silica framework. As a result, it left silica more likely affected by hydrolysis. Additional work exploring the influence of different temperatures and time of post-treatment is now required for a better understanding and process optimization. 


\section{Conclusion}

We have established that the extraction of organic templates used in the synthesis of mesoporous silica, by supercritical $\mathrm{CO}_{2}$ can be successfully conducted, if applied to materials prepared with nonionic PEO-based templates. Such an extraction is allowed by the absence of electrostatic interactions between templates and silica. Compared with the thermal treatment, the only current pertinent solution, $\mathrm{scCO}_{2}$ extraction offers several advantages: fast and green process, ability to recover and reuse the templates.

Our preliminary tests of resistance to hydrolysis are very promising: unlike many mesoporous silica, our materials do not collapse, even after having being sunk into boiling water for three hours. This resistance must still be increased. This can be done by a thermal posttreatment, but our first results are still partially inconclusive.

The synergy between $\mathrm{scCO}_{2}$ extraction and the two-step synthesis of mesoporous silica, working at moderate temperature and ambient pressure, in water, with the possibility to easily scale up the powder manufacturing and develop a large range of tailor-made porous materials, creates a true opportunity to develop an actual industrial process.

Two main items will be developed in the future: (i) optimizing the $\mathrm{scCO}_{2}$ extraction (time, temperature) as a function of the type of material and (ii) explore how a post-extraction annealing (temperature, time) can improve or modify the material, especially in increasing the hydrothermal resistance. 


\section{References}

[1] J.S. Beck, J.C. Vartuli, W.J. Roth, M.E. Leonowicz, C.T. Kresge, K.D. Schmitt, C.T.-W. Chu, D.H. Olson, E.W. Sheppard, S.B. McCullen, J.B. Higgins, J.L. Schlenker, A New Family of Mesoporous Molecular Sieves Prepared with Liquid Crystal Templates, J. Am. Chem. Soc. 114 (1992) 10834-10843.

[2] S. Inagaki, Y. Fukushima, K. Kuroda, Synthesis of Highly Ordered Mesoporous Materials from a Layered Polysilicate, J. Chem. Soc., Chem. Commun. (1993) 680-682.

[3] F. Di Renzo, H. Cambon, R. Dutartre, A 28-year-old Synthesis of Micelle-Templated Mesoporous Silica, Microporous Mater. 10 (1997) 283-286.

[4] F. Fajula, A. Galarneau, F. Di Renzo, Advanced porous materials: New developments and emerging trends, Micropor. Mesopor. Mat. 82 (2005) 227-239.

[5] A. Taguchi, F. Schüth, Ordered mesoporous materials in catalysis, Micropor. Mesopor. Mat. 77 (2005) 1-45.

[6] C.T. Kresge, M.E. Leonowicz, W.J. Roth, J.C. Vartuli, J.S. Beck, Ordered Mesoporous Molecular Sieves Synthesized by a Liquid-Crystal Template Mechanism, Nature 359 (1992) 710712 .

[7] D. Zhao, J. Feng, Q. Huo, N. Melosh, G.H. Fredrickson, B.F. Chmelka, G.D. Stucky, Triblock Copolymer Syntheses of Mesoporous Silica with Periodic 50 to 300 Ångstrom Pores, Science 279 (1998) 548-552.

[8] P. Tanev, T., T.J. Pinnavaia, A Neutral Route to Mesoporous Molecular Sieves, Science 267 (1995) 865-867.

[9] K.S. Triantafyllidis, E.F. Iliopoulou, E.V. Antonakou, A.A. Lappas, H. Wang, T.J. Pinnavaia, Hydrothermally stable mesoporous aluminosilicates (MSU-S) assembled from zeolite seeds as catalysts for biomass pyrolysis, Micropor. Mesopor. Mat. 99 (2007) 132-139.

[10] S.A. Bagshaw, E. Prouzet, T.J. Pinnavaia, Templating of Mesoporous Molecular Sieves by Nonionic Polyethylene Oxide Surfactants, Science 269 (1995) 1242-1244.

[11] E. Prouzet, C. Boissière, A review on the synthesis, structure and applications in separation processes of mesoporous MSU-X silica obtained with the two-step process, C.R. Chimie 8 (2005) 579-596.

[12] C. Boissière, A. Larbot, C. Bourgaux, E. Prouzet, C.A. Bunton, A study of the assembly mechanism of the mesoporous MSU-X silica two-step synthesis, Chem. Mater. 13(10) (2001) 3580-3586.

[13] P. Behrens, G.D. Stucky, Ordered Molecular Arrays as Templates: A New approach to the Synthesis of Mesoporous Materials, Angew. Chem. Int. Ed. 32(5) (1993) 696-699.

[14] Q. Huo, D.I. Margolese, U. Ciesla, P. Feng, T.E. Gier, P. Sieger, R. Leon, P.M. Petroff, F. Schüth, G.D. Stucky, Generalized Synthesis of Periodic Surfactant/Inorganic Composite Materials, Nature 368 (1994) 317-321.

[15] J.P. Brunelle, Preparation of Catalysts by Metallic Complex Adsorption on Mineral Oxides, Pure and Applied Chemistry 50(9-10) (1978) 1211-1229. 
[16] C. Aymonier, A. Loppinet-Serani, H. Reveron, Y. Garrabos, F. Cansell, Review of supercritical fluids in inorganic materials science, J. Supercrit. Fluids 38(2) (2006) 242-251.

[17] C. Aymonier, F. Cansell, Supercritical fluid techniques, Ann. Chim.-Sci. Mat. 31(3) (2006) 317-337.

[18] J. Peach, J. Eastoe, Supercritical carbon dioxide: a solvent like no other, Beilstein J. Org. Chem. 10 (2014) 1878-1895.

[19] E.J. Beckman, Supercritical and near-critical CO2 in green chemical synthesis and processing, J. Supercrit. Fluids 28(2-3) (2004) 121-191.

[20] R. Sui, P. Charpentier, Synthesis of Metal Oxide Nanostructures by Direct Sol-Gel Chemistry in Supercritical Fluids, Chem. Rev. 112(6) (2012) 3057-3082.

[21] J. Wang, Y. Xia, W. Wang, M. Poliakoff, R. Mokaya, Synthesis of mesoporous silica hollow spheres in supercritical CO2/water systems, J. Mater. Chem. 16(18) (2006) 1751-1756.

[22] J. Li, X. Shia, L. Wang, F. Liu, Synthesis of biomorphological mesoporous TiO2 templated by mimicking bamboo membrane in supercritical CO2, J. Coll. Interface Sci. 315(1) (2007) 230236.

[23] J.P. Hanrahan, M.P. Copley, K.J. Ziegler, T.R. Spalding, M.A. Morris, D.C. Steytler, R.K. Heenan, R. Schweins, J.D. Holmes, Pore Size Engineering in Mesoporous Silicas Using Supercritical CO2, Langmuir 21 (2005) 4163-4167.

[24] K. Ghosh, S.M. Vyas, H.-J. Lehmler, S.E. Rankin, B.L. Knutson, Tailoring porous silica films through supercritical carbon dioxide processing of fluorinated surfactant templates, J. Phys. Chem. B 111(2) (2007) 363-370.

[25] K. Ghosh, S. Bashadi, H.-J. Lehmler, S.E. Rankin, B.L. Knutson, Pore size engineering in fluorinated surfactant templated mesoporous silica powders through supercritical carbon dioxide processing, Micropor. Mesopor. Mat. 113(1-3) (2008) 106-113.

[26] M.J. Tenorio, C. Pando, J.A.R. Renuncio, J.G. Stevens, R.A. Bourne, M. Poliakoff, A. Cabanas, Adsorption of $\mathrm{Pd}(\mathrm{hfac})(2)$ on mesoporous silica SBA-15 using supercritical $\mathrm{CO} 2$ and its role in the performance of Pd-SiO2 catalyst, J. Supercrit. Fluids 69 (2012) 21-28.

[27] A. Gignone, L. Manna, S. Ronchetti, M. Banchero, B. Onida, Incorporation of clotrimazole in Ordered Mesoporous Silica by supercritical CO2, Micropor. Mesopor. Mat. 200 (2014) 291296.

[28] A.-R. Ibrahim, X. Li, Y. Zhou, Y. Huang, W. Chen, H. Wang, J. Li, Synthesis of SpongyLike Mesoporous Hydroxyapatite from Raw Waste Eggshells for Enhanced Dissolution of Ibuprofen Loaded via Supercritical CO2, Int. J. Mol. Sci. 16(4) (2015) 7960-7975.

[29] T.-D. Nguyen-Phan, H.-D. Pham, S. Kim, E.-S. Oh, E.J. Kim, E.W. Shin, Surfactant removal from mesoporous $\mathrm{TiO} 2$ nanocrystals by supercritical $\mathrm{CO} 2$ fluid extraction, J. Ind. Eng. Chem. 16(5) (2010) 823-828.

[30] Z. Huang, L. Xu, J.-H. Li, Amine extraction from hexagonal mesoporous silica materials by means of methanol-enhanced supercritical CO2: Experimental and modeling, Chem. Eng. J. 166(2) (2011) 461-467. 
[31] Z. Huang, H.-S. Li, H. Miao, Y.-h. Guo, L.-J. Teng, Modified supercritical CO2 extraction of amine template from hexagonal mesoporous silica (HMS) materials: Effects of template identity and matrix Al/Si molar ratio, Chem. Eng. Res. Des. 92(7) (2014) 1371-1380.

[32] E.A.C. Panduro, K. Assaker, T. Beuvier, J.-L. Blin, M.-J. Stebe, O. Konovalov, A. Gibaud, Nonionic Fluorinated Surfactant Removal from Mesoporous Film Using sc-CO2, ACS Appl. Mater. Interfaces 9(3) (2017) 3093-3101.

[33] M. Varache, I. Bezverkhyy, F. Bouyer, R. Chassagnon, F. Baras, F. Bouyer, Improving structural stability of water-dispersed MCM-41 silica nanoparticles through post-synthesis $\mathrm{pH}$ aging process, J. Nanoparticles Res. 17(9) (2015).

[34] R. Ryoo, S. Jun, Improvement of hydrothermal stability of MCM-41 using salt effects during the crystallization process, J. Phys. Chem. B 101(3) (1997) 317-320.

[35] J.T. Tompkins, R. Mokaya, Steam Stable Mesoporous Silica MCM-41 Stabilized by Trace Amounts of Al, ACS Appl. Mater. Interfaces 6(3) (2014) 1902-1908.

[36] C. Boissière, A. Larbot, A. van der Lee, P.J. Kooyman, E. Prouzet, A new Synthesis of Mesoporous MSU-X Silica Controlled by a Two-Step Pathway, Chem. Mater. 12 (2000) 29022913.

[37] C.J. Brinker, Hydrolysis and Condensation of Silicates: Effects on Structure, J. Non-Cryst. Solids 100 (1988) 31-50.

[38] M.A.U. Martines, E. Yeong, A. Larbot, E. Prouzet, Temperature dependence in the synthesis of hexagonal MSU-3 type mesoporous silica synthesized with Pluronic P123 block copolymer, Micropor. Mesopor. Mat. 74 (2004) 213-220.

[39] W. Hammond, E. Prouzet, S.D. Mahanti, T.J. Pinnavaia, Structure Factor for the Periodic Walls of Mesoporous MCM-41 Molecular Sieves, Micropor. Mesopor. Mat. 27 (1999) 19-25.

[40] E. Prouzet, T.J. Pinnavaia, Assembly of Mesoporous Molecular Sieves Containing Wormhole Motifs by a Nonionic Surfactant Pathway: Control of Pore Size by Synthesis Temperature, Angew. Chem. Int. Ed. 36(5) (1997) 516-518.

[41] E. Prouzet, F. Cot, G. Nabias, A. Larbot, P.J. Kooyman, T.J. Pinnavaia, Assembly of Mesoporous Silica Molecular Sieves Based on Nonionic Ethoxylated Sorbitan Esters as Structure Directors, Chem. Mater. 11(6) (1999) 1498-1503.

[42] E. Prouzet, C. Boissière, S.S. Kim, T.J. Pinnavaia, Roughness of mesoporous silica surfaces deduced from adsorption measurements, Micropor. Mesopor. Mat. 119(1-3) (2009) 9-17. 


\section{Figure Caption}

Figure 1: TGA curves for mesoporous silica prepared with T15S12 or P123 at different temperatures: (a) $\mathrm{T} 15 \mathrm{~S} 12,35^{\circ} \mathrm{C}$; (b) $\mathrm{P} 123,6^{\circ} \mathrm{C}$; (c) $\mathrm{P} 123,45^{\circ} \mathrm{C}$. Comparisons between the assynthesized (blue line), the $600^{\circ} \mathrm{C}$ calcined (green dotted) and the $\mathrm{scCO}_{2}$ extracted (black dashed) samples. Mass loss are normalized at $150^{\circ} \mathrm{C}$, once samples are fully dehydrated.

Figure 2: SAXS patterns for mesoporous silica prepared at different temperatures $\left(6^{\circ} \mathrm{C}, 21^{\circ} \mathrm{C}\right.$, $35^{\circ} \mathrm{C}, 45^{\circ} \mathrm{C}$ ) with $\mathrm{T} 15 \mathrm{~S} 12(\mathrm{a}, \mathrm{b})$ or $\mathrm{P} 123(\mathrm{c}, \mathrm{d})$, and either calcined at $600^{\circ} \mathrm{C}(\mathrm{a}, \mathrm{c})$ or $\mathrm{scCO}_{2}$ extracted $(b, d)$. (Figures c \& d are in $\log \mathrm{Y}$ axis; figures with linear axes are displayed in Figure S1).

Figure 3: Pore size distribution calculated by DFT from the adsorption branch of the nitrogen adsorption isotherm for samples prepared with $\mathrm{T} 15 \mathrm{~S} 12$ (a) treated at $600^{\circ} \mathrm{C}$ or (b) $\mathrm{scCO}_{2}$ extracted, or with $\mathrm{P} 123$ (c) treated at $600^{\circ} \mathrm{C}$ or (d) $\mathrm{scCO}_{2}$ extracted.

Figure 4: Physico-chemical characteristics of mesoporous silica prepared with T15S12 (red, top) or P123 (green, bottom) at $45^{\circ} \mathrm{C}$, submitted to different post synthesis treatments: (a) BET specific surface area; (b) Pore Size Diameter calculated by DFT (the black lines correspond to the width of the PSD peak at half-height width); (c) Pore volume calculated by DFT; (d) Surface fractal dimension Ds. 
Figure 1
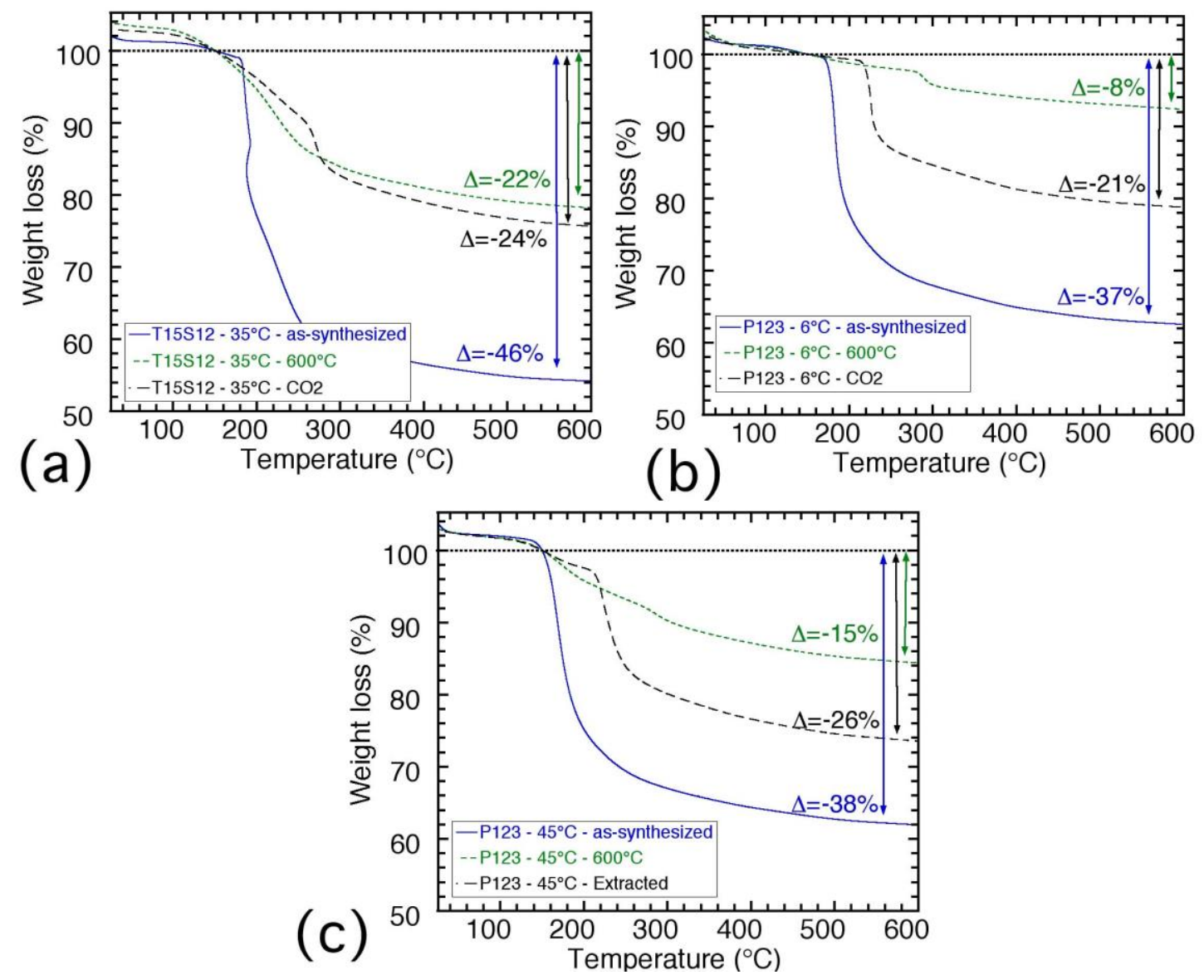
Figure 2
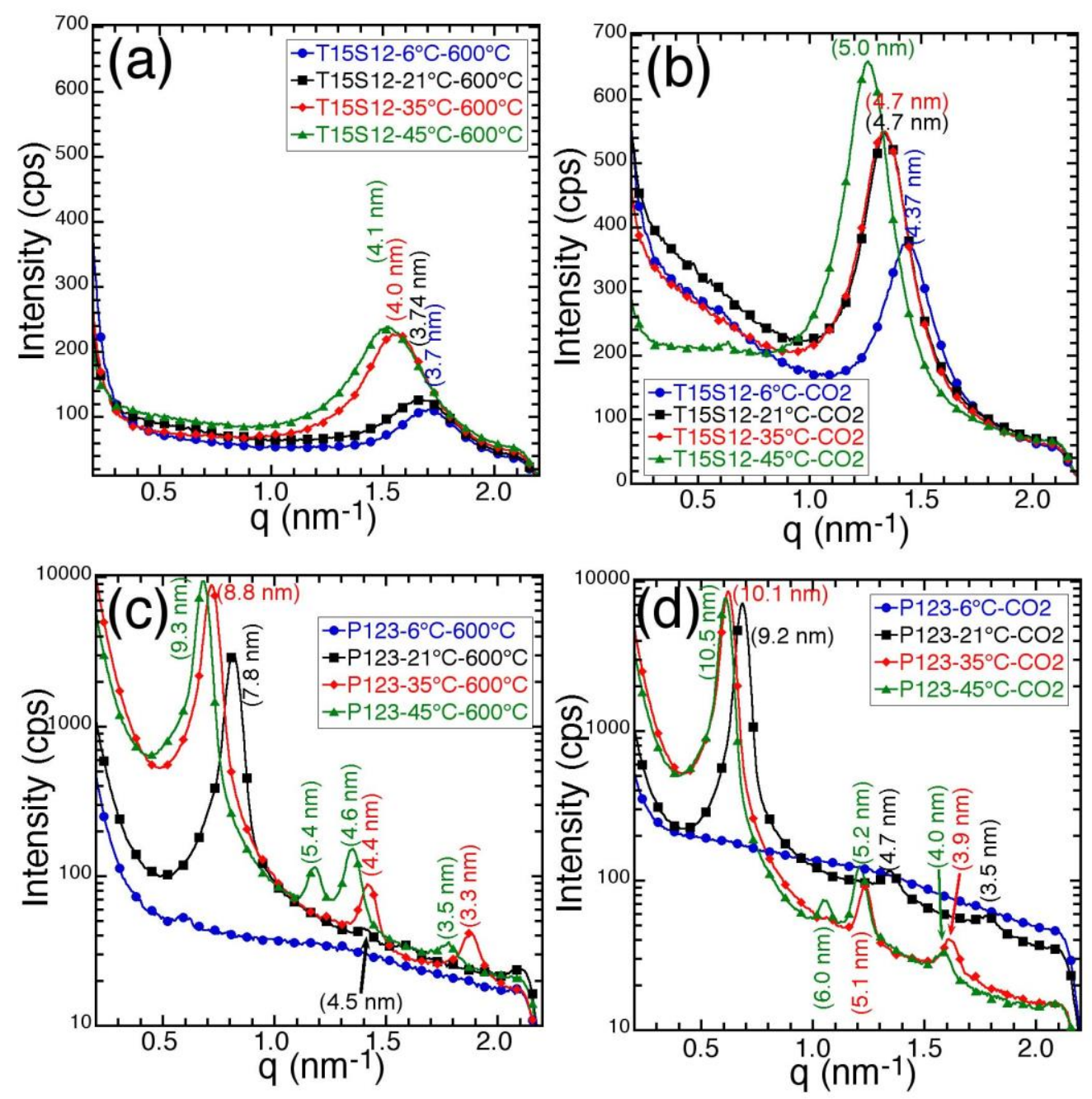
Figure 3
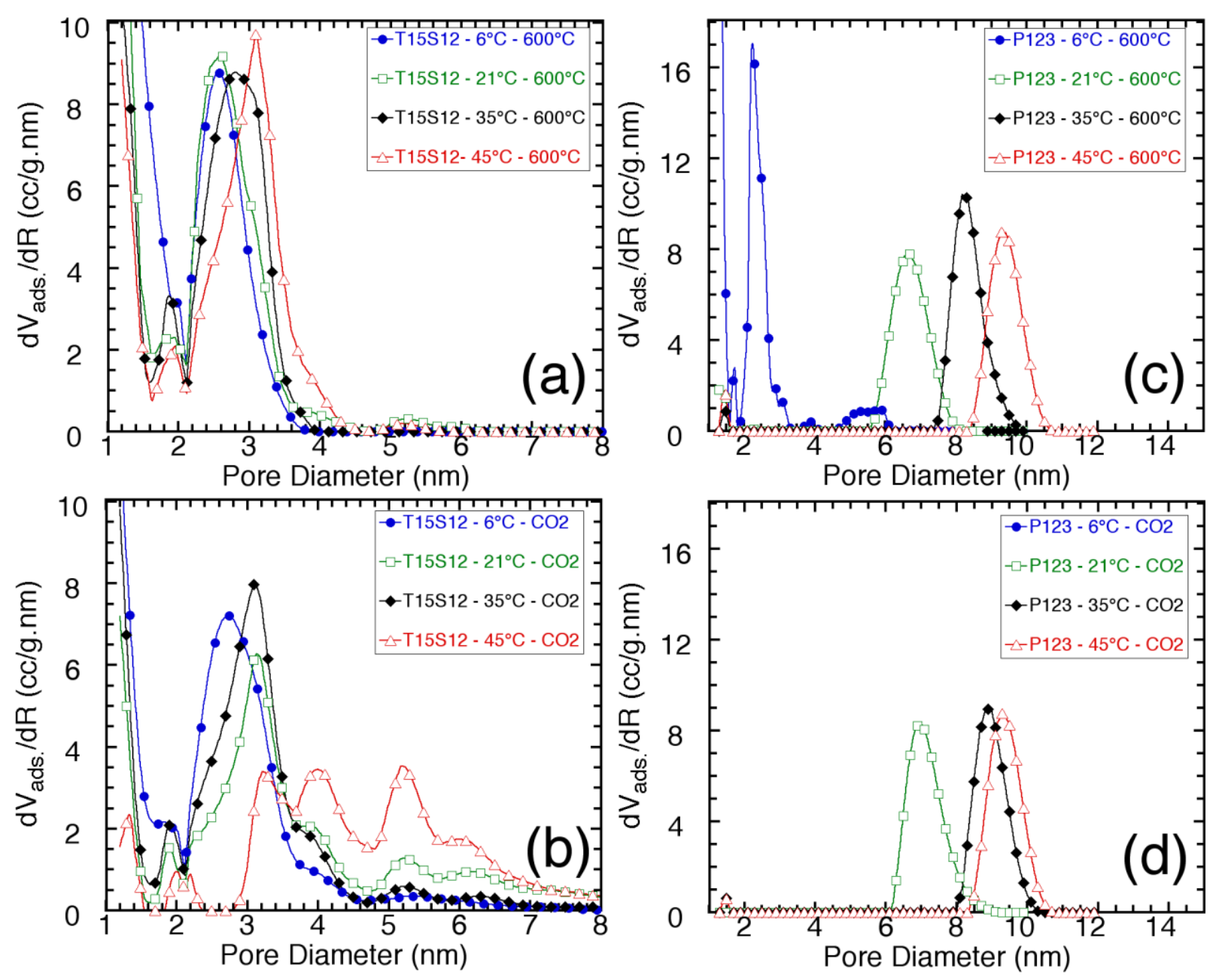
Figure 4
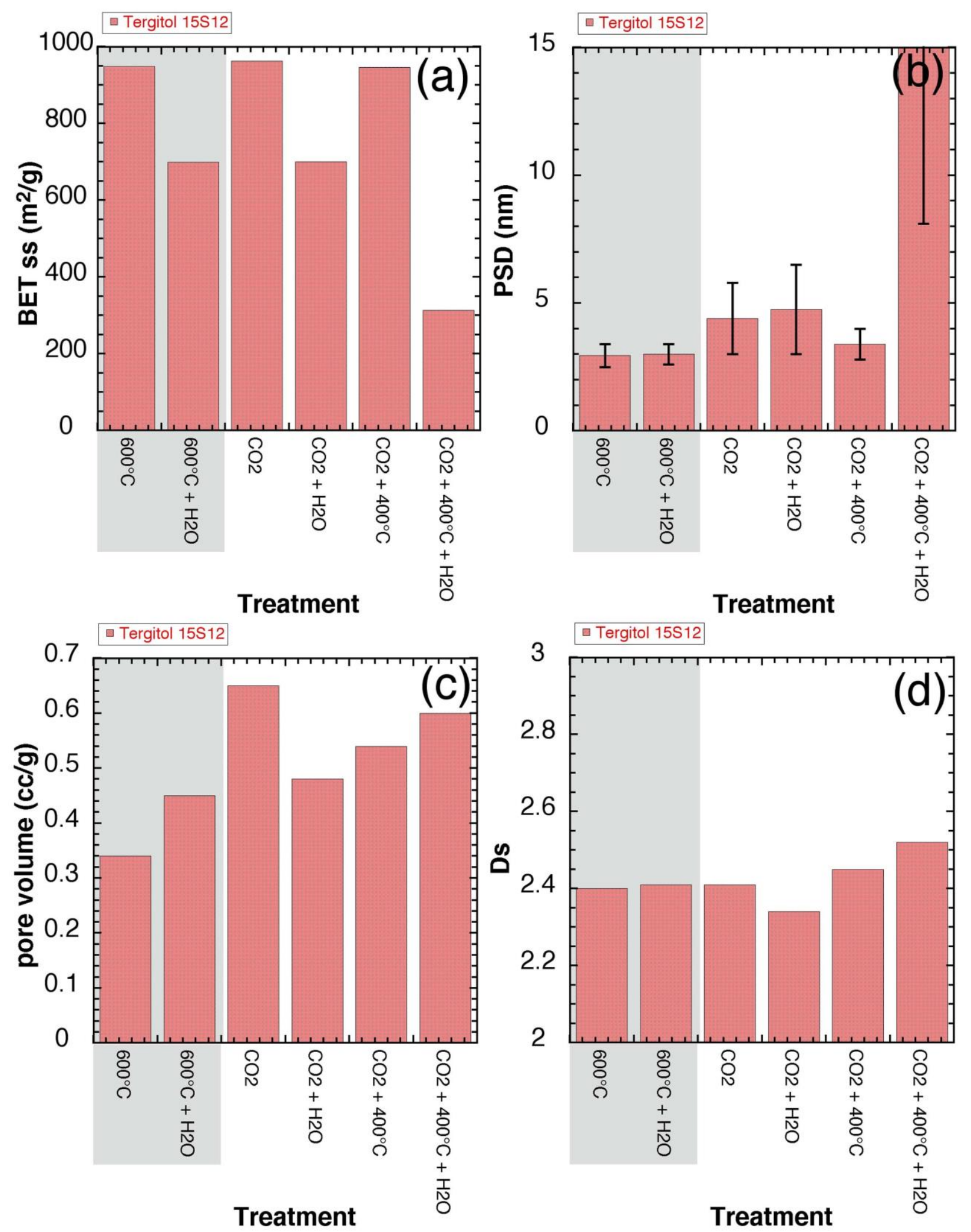
